\title{
ULTRASOUND GUIDED CONTINUOUS QUADRATUS LUMBORUM BLOCK AS A PERIOPERATIVE ANALGESIC TECHNIQUE FOR PYELOPLASTY IN A PAEDIATRIC PATIENT : A CASE REPORT
}

Yadav $R K^{1^{*}}$, Dhungel $B K^{2}$, Thapa $B^{3}$

\begin{abstract}
Affiliation
1. Assistant Professor, Anesthesia and Critical Care, Kanti Children's Hospital

2. Registrar, Anesthesia and Critical Care, Civil Service Hospital

3. Associate Professor, NAMS, Department of Paediatric Surgery, Kanti Children's Hospital
\end{abstract}

\section{ARTICLE INFO}

Received : 05 March, 2020

Accepted : 14 April, 2020

Published : 30 June, 2020

(C) Authors retain copyright and grant the journal right of first publication with the work simultaneously licensed under Creative Commons Attribution License CC - BY 4.0 that allows others to share the work with an acknowledgment of the work's authorship and initial publication in this journal.

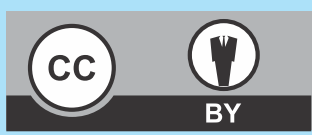

CR 31

DOI: https://doi.org/10.3126/bjhs.v5i1.29641

$$
\begin{gathered}
\text { * Corresponding Author } \\
\text { Dr Rupesh Kumar Yadav } \\
\text { Assistant Professor } \\
\text { Kanti Children's Hospital } \\
\text { Department of Anesthesia and Critical Care } \\
\text { Email: rupeshdoc905@gmail.com } \\
\text { ORCID ID: https://orcid.org/0000-0002-0607-667 }
\end{gathered}
$$

\section{Citation}

Yadav RK, Dhungel BK, Thapa B. Ultrasound Guided Continuous Quadratus Lumborum Block as A Perioperative Analgesic Technique for Pyeloplasty in A Paediatric Patient : A Case Report. BJHS 2020;5(1)11:996-999.

\section{ABSTRACT}

With the use of ultrasound, peripheral nerve blocks can be more precise and deposition of local anesthetics under direct vision reduces drug volume and minimizes untoward toxicity. It's extensive use in peri-operative period add a safety measures to reduce procedural complications. Pain in children's are often under recognized and under treated which can lead to emotional, psychological trauma for rest of their life. Peripheral nerve blocks have the advantage of greater overall safety and efficacy for lower abdominal surgeries. An abdominal truncal block technique known as Quadratus Lumborum block has emerged recently with a goal of anesthetizing the thoracolumbar nerves for somatic as well as visceral analgesia of both lower and upper abdomen. A sound knowledge of sensory supply to the genitourinary system is important for the success of regional anesthesia. We report a case of four years old child who was diagnosed as left sided pelvic ureteric junction obstruction and was planned for pyeloplasty where continuous quadratus lumborum block was used as a mode of post operative analgesia which showed a promising result.

\section{KEYWORDS}

Paediatrics, pyeloplasty, quadratus lumborum block, ultrasound. 


\section{INTRODUCTION}

Pain in children is often under recognized, under estimated and under treated even in resourceful countries. ${ }^{1,2}$ Untreated pain in childhood can lead to chronic pain as well as emotional and psychological scars for rest of the life. ${ }^{3}$ Postoperative analgesia options in children undergoing abdominal surgeries includes neuroaxial block such as lumbar epidural catheter, caudal injection, peripheral nerve blocks such as transversus abdominis plane (TAP) block, Quadratus lumborum plane block (QLB) and systemic analgesics like Opioids and NSAIDS. Systemic Opioids and Neuraxial blockade have higher risk of adverse effects and complications compared to peripheral nerve blocks. ${ }^{4}$

Caudal anesthesia is a very popular technique among pediatric anesthesiologists because of its ease of performance, high efficacy and low complication rates ${ }^{5}$ but this method has relatively short duration of analgesia compared to the peripheral nerve blocks. ${ }^{6}$ Adjucts like morphine ${ }^{7,8}$ and clonidine ${ }^{9}$ has been used to prolong the duration of caudal block analgesia but still the adverse effects of those agents like nausea, urinary retention, pruritus and respiratory depression could limit their use. ${ }^{10}$ In addition there is always a chance of inadvertent dural puncture, unwanted motor blockade of lower limbs and disturbance of bladder function with this method. ${ }^{11}$ Occult spina bifida may also pose a relative contraindication to use caudal epidural block as a part of multimodal analgesic technique. ${ }^{12}$

Peripheral nerve blocks have the advantages of greater overall safety and efficacy for lower abdominal surgeries. The past decade has experienced a remarkable growth in pediatric regional anesthesia. ${ }^{13}$ Systematic reviews have shown the use of ultrasound guidance for regional blockade in children may decrease the occurrence of failed block and increase its duration of action. ${ }^{14}$

Quadratus lumborum block (QLB) is one of the novel truncal blocks that provides analgesia to abdominal wall and viscera by anesthetizing the thoracolumbar nerves from T4 to L1 segments for somatic as well as visceral analgesia by deposition of local anesthetics in the thoracic paravertebral space. Randomized controlled trials have shown ultrasound guided QLB to have effective results ${ }^{15}$ and to be superior to both caudal and transvesus abdominis plane (TAP) blocks for pediatric lower abdominal and inguinal surgeries. ${ }^{16,17}$ The articles on continuous quadratus lumborum block in childrens are scarce, thus we aim to highlight the analgesic importance of continuous QLB in pediatric abdominal surgeries.

\section{CASE REPORT}

Four years old child weighing $12 \mathrm{~kg}$ was diagnosed as Left sided Pelvic Ureteric Junction (PUJ) Obstruction and planned for left pyeloplasty. Preoperative history, systemic review and routine biochemistry were normal except for the abdomen ultrasound, which showed left PUJ obstruction with gross hydronephrosis. Parents were counseled and written informed consent was obtained.
On arrival to the operation theatre WHO surgical safety checklist was followed and monitor attached. An intravenous line was in situ so checked for patency and induction of anaesthesia was initiated with intravenous Midazolam 0.3 $\mathrm{ml}$, Propofol 20 mg, Fentanyl 25 mcg, Paracetamol 200mg and Rocuronium $10 \mathrm{mg}$. Airway was secured with $5.0 \mathrm{~mm}$ ID cuffed ET tube and fixed after auscultation of both lung fields. Child was turned to right lateral position and under all aseptic precaution a high frequency linear probe of 3 to 12 $\mathrm{Hz}$ was placed over the anterior abdomen wall just above the umbilicus. This initial scan showed Rectus abdominis muscle. Further scanning laterally visualization of three abdominal muscles namely External Oblique, Internal oblique and Transversus abdominis muscles were seen from above downward. Scanning was continued to the back above the iliac crest which showed appearance of Quadratus lumborum, Psoas major muscle, tip of transverse process and Latissimus dorsi which was the end point of scanning. A 22 'G' Pediatric Tuohy Epidural needle was inserted by an in-plane technique to reach the plane between Quadratus lumborum and Psoas major muscle and $6 \mathrm{ml}$ of $0.25 \%$ Ropivacaine was deposited. Epidural catheter was inserted and fixed at the same time. The child was then turned back to supine position. Maintenance of anaesthesia was done with $\mathrm{O} 2+$ Isoflurane+Rocuronium and positive pressure ventilation. Intraoperative blood loss was around $50 \mathrm{ml}$ and was replaced with crystalloids, rest other events were uneventful. The surgery lasted for 70 minutes and on completion of surgery extubation was done with adequate dose of reversal. Child was shifted to surgical intensive care unit (SICU).

Postoperative analgesia was maintained with continuous Infusion of Ropivacaine 0.125 \% @ 1.5 ml per hour via QL Catheter and IV Paracetamol $180 \mathrm{mg}$ eight hourly. FLACC (Face, Legs, Activity, Cry, Consolability ) scoring system was used for pain assessment every hourly along with monitoring of other routine vitals and whenever the child was anxious or any fluctuation in hemodynamics was noticed. The FLACC score was $0 / 10$ during the entire stay at SICU. Rescue analgesia of $25 \mathrm{mcg}$ Fentanyl was advised if the FLACC score exceed 3 at any point, however it wasn't required. The catheter was taken out on the $3^{\text {rd }}$ postoperative day and shifted to surgical ward. On $7^{\text {th }}$ postoperative day the child was discharged to home.

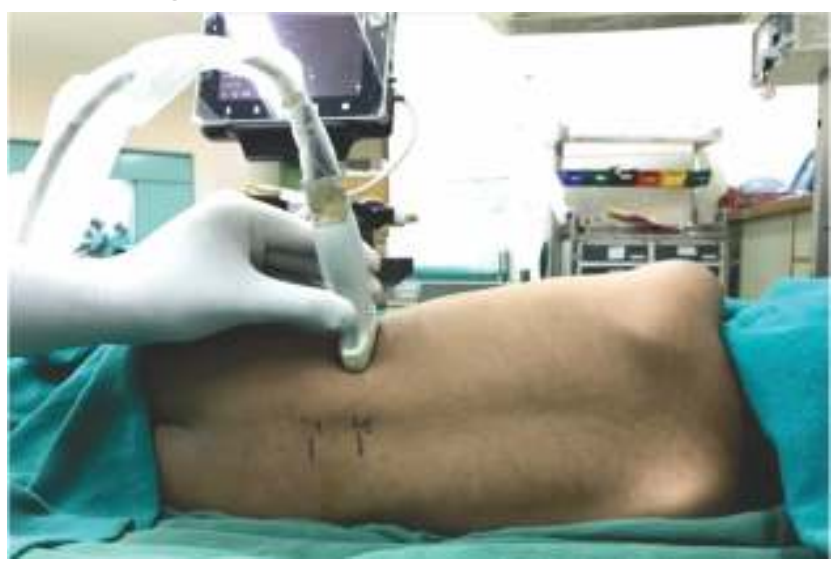

Figure 1: Child on Right Lateral position, (Quadratus Lumborum Scanning with Linear Probe). 


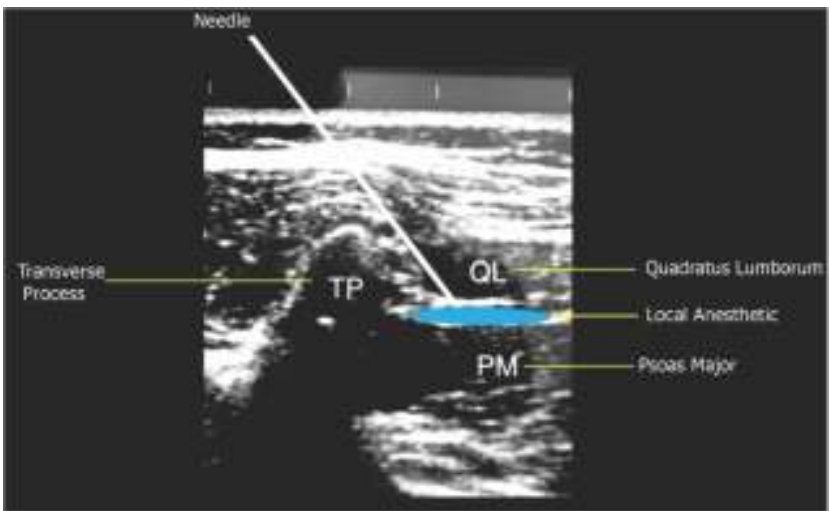

Figure 2 : Ultrasound Image showing Quadratus Lumborum block.

\section{DISCUSSION}

Quadratus lumborum plane block was first described by Blanco et al. in $2007 .^{18}$ In this technique local anesthetic is injected in the thoracolumbar fascia adjacent to the quadratus lumborum muscle that results in its spread medially and cranially under the crura and arcuate ligaments of the diaphragm and further onto the thoracic paravertebral space (PVS). ${ }^{19}$ This results in the blockade of T4 to L1 dermatomes. ${ }^{19}$ This hypothesis is supported by various imaging studies that showed the drug distribution pattern in the QLB to be more similar to a paravertebral block than to TAP block. ${ }^{20-22}$ The visceral analgesia that occurs is due to the spread of anesthetics drugs to the celiac ganglion or sympathetic trunk via splanchnic nerves, as is the case with the paravertebral block ${ }^{23}$. Several needle approaches and injection sites have been proposed. Blanco originally labeled some anterior injection locations as type 1 and type 2, but has since referred to type 2 as the "QLB" because of the greater analgesia with the more posterior type 2 approach. Type 3 quadratus lumborum block is the one in which transmuscular injection of local anaesthetic agents occurs between quadratus lumborum and psoas

\section{REFERENCES}

1. Beltramini A, Milojevic K, Pateron D. Pain Assessment in Newborns, Infants, and Children. Pediatr Ann. 2017;46(10):e387-e395. doi:10.3928/19382359-20170921-03.

2. Velazquez Cardona C, Rajah C, Mzoneli YN, Friedrichsdorf SJ, Campbell F, Cairns C, Rodseth RN. An audit of paediatric pain prevalence, intensity, and treatment at a South African tertiary hospital. Pain Rep. 2019 Dec 6;4(6):e789. doi: 10.1097/ PR9.0000000000000789. PMID: 31984294

3. Mathews L. Pain in children: neglected, unaddressed and mismanaged. Indian J Palliat Care. 2011 Jan;17(Suppl):S70-3. doi: 10.4103/0973-1075.76247. PMID: 21811376; PMCID: PMC3140088.

4. 4. Polaner DM, Taenzer AH, Walker BJ, et al. Pediatric Regional Anesthesia Network (PRAN): a multi-institutional study of the use and incidence of complications of pediatric regional anesthesia. AnesthAnalg. 2012;115:1353-1364

5. Giaufré E, Dalens B, Gombert A. Epidemiology and morbidity of regional anesthesia in children: a one-year prospective survey of the French-Language Society of Pediatric Anesthesiologists. Anesth Analg. 1996;83:904-912. major muscle. ${ }^{24}$ Several authors have successfully used single shot QLB in pediatric age group for various abdominal and thoracic surgeries. ${ }^{25-27}$ Several Randomized controlled trials have also shown single shot QL to be superior. ${ }^{28-30}$ But to our knowledge studies that reported the use of continuous QL block in this age group is scarce. In our case the continuous infusion not only facilitated maintenance of surgical anesthesia with lower amounts of anesthetics intraoperatively but also allowed for complete avoidance of opioid during the patient's entire hospital stay. This is in contrast, to our institution's current practice for this procedure. Typical analgesic management of children includes a ropivacaine $0.2 \%, 0.75-1.25 \mathrm{ml} / \mathrm{kg}$ caudal with intraoperative short acting opioid (fentanyl $2-4 \mu \mathrm{g} / \mathrm{kg}$ ) and post-operative rescue opioid as needed along with ketorolac and acetaminophen. A continuous QL block has allowed us to avoid the need for a caudal. The dose of Ropivacaine that we used, $0.125 \%$ @ $1.5 \mathrm{ml}$ per hour is well in agreement with several authors ${ }^{31-33}$ and did not produce any toxicity.

With the lower risk profile of an QLB compared to central blocks, this may be of added benefit. In addition, with the uncertainty of long term neurological side effects of general anesthesia on infants, utilizing an QL catheter may allow for adequate surgical anesthesia with minimal additional anesthetic.

\section{CONCLUSION}

The recently introduced QLB, as a single shot or continuous infusion, may be a good option for abdominal and lower abdominal surgeries in pediatric patients as well. The continuous QL block can provide an opioid free analgesic alternative with satisfactory pain control. However further prospective trials comparing QL block with current analgesic techniques are needed to get a convincing result.

\section{CONFLICT OF INTEREST}

None
6. Ecoffey C, Lacroix F. Epidemiology and morbidity of regional anesthesia in children: a follow-up one-year prospective survey of the FrenchLanguage Society of PaediatricAnaesthesiologists (ADARPEF). PediatrAnesth. 2010;20:1061-1069.

7. Jöhr M, Berger TM. Caudal blocks. PediatrAnaesth. 2012;22:44-50.

8. Sato M, lida T, Kikuchi C, Sasakawa T, Kunisawa T. Comparison of caudal ropivacaine-morphine and paravertebral catheter for major upper abdominal surgery in infants. PediatrAnesth. 2017;27:524-530.

9. Singh R, Kumar N, Singh P. Randomized controlled trial compar-ing morphine or clonidine with bupivacaine for caudal analgesia in children undergoing upper abdominal surgery. $\mathrm{Br} J$ Anaesth. 2011;106:96-100.

10. Krane EJ. Delayed respiratory depression in a child after caudal epidural morphine. AnesthAnalg. 1988;67:79-82.

11. Menzies R, Congreve K, Herodes V, Berg S, Mason D. A survey of pediatric caudal extradural anesthesia practice. Paediatric Anaesthesia 2009; 19: 829-836. doi: 10.1111/j.1460- 9592.2009. 03116.x 
12. Koo BN, Hong JY, Song HT. Ultrasonography re- veals a high prevalence of lower spinal dysraphism in children with urogenital anomalies. Acta Anaesthesiol Scand. 2012;56:624-628.

13. Walker BJ, Long JB, Sathyamoorthy $M$, et al. Complications in pediatric regional anesthesia:ananalysis of more than 100,000 blocks from the Pediatric Regional Anesthesia Network. Anesthesiology 2018; 129:721-732

14. Guay J, Suresh S, Kopp S. The use of ultrasound guidance for perioperative neuraxial and peripheral nerve blocks in children. Cochrane Database of Systematic Reviews 2019, Issue 2.

15. Visoiu M, Yakovleva N. Continuous postoperative analgesia via quadratus lumborum block - an alternative to transversus abdominis plane block. PaediatrAnaesth 2013; 23:959-961

16. Oksuz G, Bilal B, Gurkan $Y, €$ et al. Quadratus lumborum block versus transversus abdominis plane block in children undergoing low abdominal surgery: a randomized controlled trial. Reg Anesth Pain Med 2017; 42:674-679.

17. Sato M. Ultrasound-guided quadratus lumborum block compared to caudal ropivacaine/morphine in children undergoing surgery for vesicoureteric reflex. PaediatrAnaesth 2019; 29:738-743.

18. Blanco, Rafael. (2007). TAP block under ultrasound guidance: The description of a 'no pops trechnique'. Regional Anesthesia and Pain Medicine-REGION ANESTH PAIN MED. 32. 130-130. 10.1016/j.rapm. 2007.06.268

19. Dam M, Moriggl B, Hansen CK. The pathway of injectate spread with the transmuscular quadratus lumborum block: a cadaver study. AnesthAnalg 2018; 125: 303e12

20. Carney J, Finnerty O, Rauf J. Studies on the spread of local anaesthetic solution in transversus abdominis plane blocks. Anaesthesia 2011;66: 1023-30

21. Børglum J, Jensen K. Abdominal surgery: advances in the use of ultrasound-guided truncal blocks for perioperative pain management. In: Derbel F, ed. Abdominal Surgery. Rijeka, Croatia: InTech, 2012:69-94

22. Børglum J, Christensen AF, Hoegberg LCG. Bilateral- dual transversus abdominus (BD-TAP) block or thoracic para- vertebral block (TPVB)? Distribution patterns, dermatomal anesthesia and LA pharmacokinetics. Reg Anesth Pain Med 2012;37:E136-9

23. Akerman M1, Pejčić N2, Veličković I. A review of the quadratus lumborum block and ERAS. Frontiers in Medicine (Lausanne). 2018; 26; 5: 44. doi:10.3389/fmed.2018.00044
24. Chiao F, Jung B et al. Quadratus Lumborum Block: A More Extensive Spread and Longer-Lasting Alternative to the Tranversus Abdominus Plane Block?SPA news. 2016; 29; 3.

25. Visoiu $\mathrm{M}$, Yakovleva $\mathrm{N}$ : Continuous postoperative analgesia via quadratus lumborum block:An alternative to transversus abdominis plane block. PaediatrAnaesth 2013; 23:959-61

26. Aksu C, Gürkan Y: Ultrasound guided quadratus lumborum block for postoperative analgesia in pediatric ambulatory inguinal hernia repair. J ClinAnesth 2018; 46:77-8

27. Baidya DK, Maitra S, Arora MK, Agarwal A: Quadratus lumborum block: An effective method of perioperative analgesia in children undergoing pyeloplasty. J ClinAnesth 2015; 27:694-6

28. Oksüz G, Bilal B, Gürkan Y, Urfalioğlu A. Quadratus lumborum block versus transversus abdominis plane block in children undergoing low abdominal surgery:A randomized controlled trial. Reg Anesth Pain Med 2017; 42:674-9

29. Samerchua, A, Leurcharusmee, P, Panichpichate, K, et al. A Prospective, randomized comparative study between ultrasoundguided posterior quadratus lumborum block and ultrasound-guided ilioinguinal/iliohypogastric nerve block for pediatric inguinal herniotomy. PediatrAnesth. 2020; 00: 1-8. https://doi.org/10.1111/ pan.13837

30. Sato M. Ultrasound-guided quadratus lumborum block compared to caudal ropivacaine/ morphine in children undergoing surgery for vesicoureteric reflex. PediatrAnesth. 2019;00:1-6. https://doi.org/ $10.1111 /$ pan. 13650

31. Murouchi T, Iwasaki S, Yamakage M: Chronological changes in ropivacaine concentration and analgesic effects between transversus abdominis plane block and rectus sheath block. Reg Anesth Pain Med 2015; 40:568-71

32. Chakraborty A, Goswami J, Patro V. Ultrasound-guided continuous quadratus lumborum block for postoperative analgesia in a pediatric patient: Acase report. 2015;4(3):34-36. doi:10.1213/XAA.000000 0000000090.

33. Visoiu M, Yakovleva N. Continuous postoperative analgesia via quadratus lumborum block - An alternative to transversus abdominis plane block. PaediatrAnaesth. 2013;23(10):959-961. doi:10.1111/pan.12240. 